\title{
Removal of Hexavalent Chromium Ions from Aqeous Medium using Chitosan Magnetic Nanocomposite Modified with Hexamine
}

\author{
Najat J. Saleh, Saad R. Sulttan, Amina J. Khazm. \\ Chemical Engineering Department, University of Technology
}

\begin{abstract}
This work integrates nanotechnology, adsorption, and magnetic separation to remove chromium $(\mathrm{Cr})$ pollutant from industrial wastewater using magnetic nanoparticles. The magnetic nanocomposite consists of chitosan biopolymer and iron $\left(\mathrm{Fe}_{3} \mathrm{O}_{4}\right)$ magnetic nanoparticles. The $\mathrm{Fe}_{3} \mathrm{O}_{4}$ magnetic nanoparticles were prepared by chemical co-precipitation technique and the chitosan magnetic nanocomposite (CMNC) was prepared by Ex situ process. Moreover, anoval amination of CMNC with hexamine to get functionalized $\mathrm{CMNC}$ was performed to remove $\mathrm{Cr}$ (VI) in wider range of $\mathrm{pH}$. The prepared $\mathrm{Fe}_{3} \mathrm{O}_{4}$ magnetic nanoparticles, $\mathrm{CMNC}$ and functionalized $\mathrm{CMNC}$ were characterized using different analytical techniques, XRD, FTIR, AFM, SEM, EDX and TGA.
\end{abstract}

Batch adsorption was employed to determine the effects of $\mathrm{pH}$. The adsorption results show that the functionalized CMNC possessed high activity for $\mathrm{Cr}$ (VI) removal in any condition of acidic, neutral and basic solutions with the percentage sorption of chromium reached to $91.7 \%$.

Sorption isotherms were fitted with the Langmuir, Freundlich and Temkin models, it was found that the Freundlich isotherm model have the best fit with $\mathrm{R}^{2}=0.998$ with functionalized CMNC. The kinetic data of $\mathrm{Cr}$ (VI) sorption with functionalized CMNC were fitted well with the pseudo-second order kinetic model. The reuse of the functionalized $\mathrm{CMNC}$ indicates that the adsorbent material is more than $80 \%$ adsorption capacity after five regeneration cycles. The results of this work shown that functionalized CMNC is a potential adsorbent to removal of $\mathrm{Cr}(\mathrm{VI})$ contaminated in a wider range of $\mathrm{pH}$.

Keywords: Chitosan, Magnetic, Nanocomposite, adsorption, Hexavalent Chromium.

Paper History (Received :30-5-2018; Accepted :7-32019)

\section{Introduction}

The disposal of large quantities of wastewater due to the increase in industrial processes pollute the water with oils, metal ions, chemicals, fines and alternative materials. The presence of heavy metals ions in water bodies causes severe public health and environmental issues. Recently, hexavalent chromium component has been given due to its negative effects, which is detrimental to human health [Hong Li, 2016, Vaishnavi S. et al., 2015].

Adsorption is one of the most important techniques used in heavy metal processing and is widely used because of the simplicity of operation and low costs. Currently nanoparticles became the most important adsorbents used in water purification because of their properties. Their applications are making easy by properties such as larger surface areas compared to bulk particles and therefore the ability to be functionalized with numerous chemical teams to extend their likeness towards target compounds [Shahriar M. et al., 2012].

Separation of pollutants by magnetic materials becomes common and fascinating in recent years. The removal of pollutants from wastewater by employing a typical adsorbent has many limitations particularly within the recollection of adsorbents when surface assimilation method, by introducing magnetic property into typical adsorbents, recollection when separation might be achieved thus simply that the lost of adsorbents might be lowered [Dong C. et al., 2014].

This work is used to remove chromium contaminants from synthetic wastewater using magnetic nanoparticles Removal of chrome ion by magnetic nanocomposite have been published in several articles. However, most of magnetic nanocomposite were solely effective in lower $\mathrm{pH}$ because of the protonation of the amine groups, although $\mathrm{Cr}(\mathrm{VI})$ exists not solely within the acidic however conjointly in neutral and basic wastewater. Therefore, magnetic nanocomposite that might be applied on removal of $\mathrm{Cr}(\mathrm{VI})$ in wide range of hydrogen ion concentration was needed [Vaishnavi S. et al., 2015 ; Pooja S.,\& Nagendran R., 2013 ;Kyzas et al., 2009 and Khalid Z., 2010]. Functionalized of magnetic nanocomposite with hexamine groups make it positively charged at wide range of $\mathrm{pH}$ so that it could be applied effectively in wider range of $\mathrm{pH}$.

\section{Materials and Methods}

Chitosan (molecular weight, $\mathrm{MW}=400,000$, degree of deacetylation, 85\%) was obtained from Sigma-Aldrich Chemicals, reagents Magnetite $\left(\mathrm{Fe}_{3} \mathrm{O}_{4}\right)$, Ferric chloride $\left(\mathrm{FeCl}_{3}\right)$, and Ferrous sulfate heptahydrate $\left(\mathrm{FeSO}_{4} \cdot 7 \mathrm{H}_{2} \mathrm{O}\right)$ were purchased from Himedia- India. Sodium hydroxide $(\mathrm{NaOH})$, Potassium dichromate $\left(\mathrm{K}_{2} \mathrm{Cr}_{2} \mathrm{O}_{7}\right)$, Ammonium hydroxide $\left(\mathrm{NH}_{4} \mathrm{OH}\right)$ and Glacial acetic acid $\left(\mathrm{CH}_{3} \mathrm{COOH}\right)$ were purchased from BDH-England. 


\section{Preparation of $\mathrm{Fe}_{3} \mathrm{O}_{4}$ Magnetic Nanoparticles}

The $\mathrm{Fe}_{3} \mathrm{O}_{4}$ Magnetic nanoparticle preparation by chemical co-precipitation technique. $13.9 \mathrm{gm}$ of $\mathrm{FeSO}_{4} \cdot 7 \mathrm{H}_{2} \mathrm{O}$ dissolved in $100 \mathrm{ml}$ of distilled water is mixed with $27.05 \mathrm{gm}$ of $\mathrm{FeCl}_{3}$ dissolved in $100 \mathrm{ml}$ of distilled water with constant stirring until it forms a transparent solution. Then, $\mathrm{NH}_{4} \mathrm{OH}$ is added slowly drop by drop to the solution with continous stirring until the $\mathrm{pH}$ of the solution becomes 10. A dark colored preciptate is formed at the end of reaction which is the $\mathrm{Fe}_{3} \mathrm{O}_{4}$ nanoparticles. The particles are separated using an external magnet and then dried in an oven [Jassal P. et al., 2015].

\section{Preparation of Chitosan Magnetic Nanocomposite (CMNC)}

$2 \mathrm{gm}$ of chitosan is dissolved in 2 vol\% glacial acetic acid. The solution was sonicated for 20 minutes, and then stirred for 18 hours. $0.1 \mathrm{~g}$ of $\mathrm{Fe}_{3} \mathrm{O}_{4}$ nanoparticles were added to the solution and flipped again for 6 hours to obtain a chitosan-magnetite nanocomposite solution. The solution was then poured onto petriplate and allowed to dry at room temperature for 48 hours [Khalid Z. , 2010].

\section{Functionalized CMNC with Hexamine}

Amination of $\mathrm{CMNC}$ with Hexamine to get functionalized CMNC was performed in two steps. First, one gram of CMNC was immersed in $20 \mathrm{~mL}$ of methanol. 1,2-Dibromoethane $(2.37 \mathrm{~mL})$ was added into the mixture drop wise and the mixture was then refluxed for $24 \mathrm{~h}$. The solid product was separated from the mixture using an external magnet and then washed with ethanol and dried in an oven at $40^{\circ} \mathrm{C}$ for $12 \mathrm{~h}$. Next, the solid product resulted from the first step was immersed in $20 \mathrm{~mL}$ methanol and hexamine $(0.83 \mathrm{gm})$ was added to the mixture and then was refluxed for $12 \mathrm{~h}$ under continuous stirring. Finally the obtained product was separated with an external magnet, washed with ethanol and deionized water for several times and dried in an oven for $24 \mathrm{~h}$ at 40 ${ }^{\circ} \mathrm{C}$.

\section{Adsorbent Characterization}

The prepared magnetic nanoparticle and the CMNC samples were characterized using different analytical techniques by X-Ray diffraction- Shimadzu-6000, Origin: Japan, Fourier transform infrared spectroscopyPerkin Elmer Spectrum FTIR instrument, atomic force microscope-Park AFM XE-100 a Zeiss Supra 35VP, SEM EDX instrument and thermogravimetric analyzer TGA/DTA (Perkin Elmer TGA7). Heavy metal ion analysis were done using Atomic absorption spectrometry (AA-6300, Germany).

\section{Batch Adsorption Experiments}

So as to describe the sorption behavior of $\mathrm{Cr}$ onto $\mathrm{CS}$, $\mathrm{CMNC}$ and functionalized (CMNC) in aqueous phase, a single component sorption experiments were conducted employing $\mathrm{K}_{2} \mathrm{Cr}_{2} \mathrm{O}_{7}$ as a representative of $\mathrm{Cr}$. The standard solutions that contain $(10,20,30,40,50,60$ and 70) $\mathrm{mg} / \mathrm{L}$ of $\mathrm{Cr}(\mathrm{VI})$ using $\mathrm{K}_{2} \mathrm{Cr}_{2} \mathrm{O}_{7}$ from stock solutions using dilution method.

\section{Adsorption Isotherms}

The experimental adsorption isotherm for $\mathrm{Cr}(\mathrm{VI})$ removal was performed at room temperature $\left(25 \pm 2^{\circ} \mathrm{C}\right)$ using synthesized samples of functionalized CMNC. Adsorption isotherms were obtained at $\mathrm{pH} 5$ by mixing 20 $\mathrm{mL}$ of $\mathrm{Cr}(\mathrm{VI})$ solutions of different concentrations (10, $20,30,40,50,60$ and $70 \mathrm{mg} / \mathrm{l}$ ) with amount of the two synthesized $0.1 \mathrm{~g}$ of were previously sealed and closed, and the suspensions were stirred by electrical water bath shaker [Type: BS-21, Origin: Germany] at $200 \mathrm{rpm}$. The amount of $\mathrm{Cr}(\mathrm{VI})$ adsorbed was calculated by subtracting the amount found in the liquid after adsorption from the amount of $\mathrm{Cr}(\mathrm{VI})$ existing before the addition of the adsorbent by atomic absorption spectrometry (AAS). The adsorption data for $\mathrm{Cr}(\mathrm{VI})$ was fitted to Langmuir, Freundlich and Temkin isotherms represented by equation 1,2 and 3.

\section{Kinetic and Intraparticle Diffusion Models}

The adsorption kinetics experiments by using functionalized CMNC were performed in conical flasks containing $20 \mathrm{ml}$ of $\mathrm{Cr}(\mathrm{VI})$ solution of $10,20,30,40,50,60,70, \mathrm{mg} / \mathrm{l}$ concentration and $\mathrm{pH}$ 5-9. A $0.1 \mathrm{~g}$ and functionalized CMNC was added to the flask at room temperature $\left(25 \pm 2^{\circ} \mathrm{C}\right)$. The mixture was stirred by electrical shaker at $200 \mathrm{rpm}$. An equilibrium study was performed by taking the sample for analysis at regular intervals from 10 To $300 \mathrm{~min}$.

The adsorbent was separated for the short-time experiments to avoid potential interference from suspended scattering particles in the atomic absorption spectrometry (AAS). The rate of sorption was calculated using three kinetic models, namely pseudo-first-order, pseudo-second-order and Intraparticle diffusion.

\section{Sorption Thermodynamics}

The thermodynamic parameters for the sorption of chromium on functionalize $\mathrm{CMNC}$ at different temperatures $\left(30,50,70{ }^{\circ} \mathrm{C}\right)$ were performed in conical flasks containing $20 \mathrm{ml}$ of chromium solution of $30 \mathrm{mg} / \mathrm{l}$ concentration and $\mathrm{pH}$ (5-9). A $0.1 \mathrm{~g} \mathrm{CS}$ and 0.1 and functionalized CMNC was added to the flasks. The solution was mixed by electrical shaker at $200 \mathrm{rpm}$. An equilibrium study was performed by taking the sample from the shaker at $200 \mathrm{~min}$.

\section{Regeneration of adsorbent}

The recovered adsorbent was rinsed after the batch balance studies with moderate distillation to remove the remaining $\mathrm{Cr}(\mathrm{VI})$ particles and then dry them. The dried 
sorbent was placed in a solution containing $200 \mathrm{ml}$ of 0.1 $\mathrm{M} \mathrm{NaCl}$ for 2 hours. This cycle was repeated for five times.

\section{Results and Discussion}

\section{Characterization of $\mathrm{Fe}_{3} \mathrm{O}_{4}$ Magnetic Nanoparticles}

The structural analysis of prepared $\mathrm{Fe}_{3} \mathrm{O}_{4}$ magnetic nanoparticles was checked by using X-ray diffractometer (XRD) and the results are shown in Fig. 1. The XRD of
$\mathrm{Fe}_{3} \mathrm{O}_{4}$ magnetic nanoparticles show six characteristic peaks of $\mathrm{Fe}_{3} \mathrm{O}_{4}$ confirming that the resultant nanoparticles consists of $\mathrm{Fe}_{3} \mathrm{O}_{4}$ with a spinel structure. The results showed that the coating process did not change in the $\mathrm{Fe}_{3} \mathrm{O}_{4}$ phase. The peaks corresponding to (hkl) values of (220), (311), (400), (422), (511) and (440) located at $30.22,35.56,43.22,53.70,57.12$ and 62.72 degrees were characteristic of $\mathrm{Fe}_{3} \mathrm{O}_{4}$ with a face-centred-cubic structure. The result obtained in the present study are in good agreement with those obtained by [Peng W. et al.,2013].

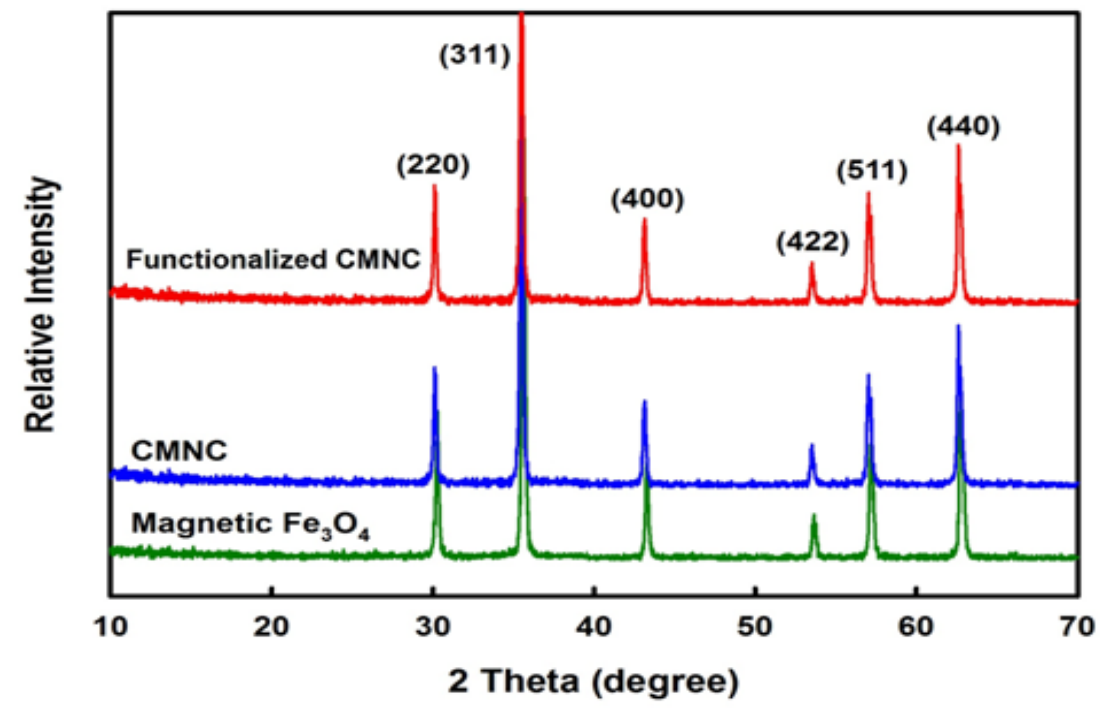

Fig. 1 X-ray diffractometer of magnetic $\mathrm{Fe}_{3} \mathrm{O}_{4}, \mathrm{CMNC}$ and functionalized CMNC.

The XRD structural analysis of chitosan magnetic nanocomposite $(\mathrm{CMNC})$ and functionalized $\mathrm{CMNC}$ are shown in Fig. 1. The results show the same six characteristic peaks of $\mathrm{Fe}_{3} \mathrm{O}_{4}$ confirming that the resultant nanoparticles consist of $\mathrm{Fe}_{3} \mathrm{O}_{4}$. The results showed that the coating process did not change in the $\mathrm{Fe} 3 \mathrm{O} 4$ phase. These results are consistent with what has already been reported magnetite chitosan prepared by different methods [Thinh N. et al.,2013; Peng W.,2013]. In comparison with $\mathrm{Fe}_{3} \mathrm{O}_{4}$ magnetic nanoparticles, the diffraction peaks of $\mathrm{CMNC}$ and functionalized CMNC have no significant difference. It means that there is no change in the structure of $\mathrm{Fe}_{3} \mathrm{O}_{4}$ during functionalization with hexamene.

Fig. 2 a shows the result of the FTIR analyses of prepared $\mathrm{Fe}_{3} \mathrm{O}_{4}$ magnetic nanoparticles by chemical coprecipitation technique. It is illustrated that the strong absorption band at $586 \mathrm{~cm}^{-1}$ is due to $\mathrm{Fe}-\mathrm{O}$ bond vibrations, which prove the $\mathrm{Fe}_{3} \mathrm{O}_{4}$ nanoparticles formation. Many researches were description the characteristic absorption of $\mathrm{Fe}-\mathrm{O}$ band in $\mathrm{Fe}_{3} \mathrm{O}_{4}$ be at 586 $\mathrm{cm}^{-1}$. Also, the result is in agreement with the result obtained by [Waldon R., 2008; Dong W. et al., 2012; Peng W., 2013a].

FTIR was analyzed for the chitosan magnetic nanoparticles (CMNC) and functionalized CMNC are shown in Figs. 2 b \&c. It is illustrated by the figure that the addition of chitosan to the nanoparticles show the peak of iron with the peaks of the original chitosan, which consists of $3327.36 \mathrm{~cm}^{-1}$ for $\mathrm{O}-\mathrm{H}$ bond stretching $\mathrm{N}-\mathrm{H}$ bond stretching, $2926 \mathrm{~cm}^{-1}$ for $\mathrm{C}-\mathrm{H}$ stretching, The band at $1246 \mathrm{~cm}^{-1}$ can be attributed to $\mathrm{C}-\mathrm{N}$ stretching vibration and the band at $1016.34 \mathrm{~cm}^{-1}$ to the stretching vibration mode of the hydroxyl group., $1653 \mathrm{~cm}^{-1}$ for $\mathrm{C}=\mathrm{O}$ of $\mathrm{NH}=\mathrm{C}=\mathrm{O}$ bond stretching, $601 \mathrm{~cm}^{-1}$ for $\mathrm{Fe}-\mathrm{O}$ group due to pure $\mathrm{Fe}_{3} \mathrm{O}_{4}$. As for the functionalized $\mathrm{CMNC}$, it turned out that the peaks of the amin was more pronounced because of its presence in hexamine. These results are in agreement with previously reported by [Jucély D. et al., 2015; peng w., 2013]. 

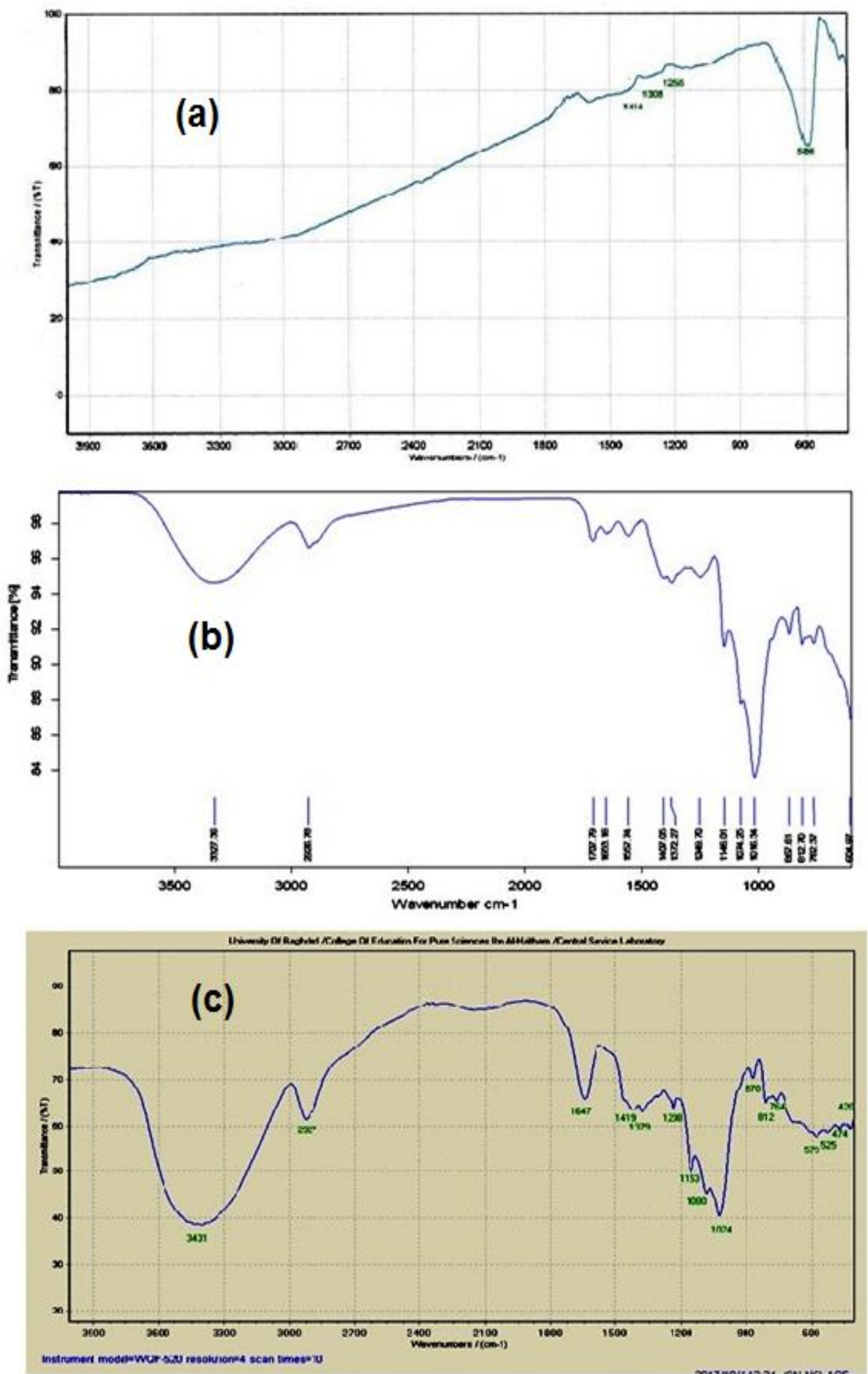

Fig. 2(a) The infrared spectrum of $\mathrm{Fe}_{3} \mathrm{O}_{4}$ magnetic nanoparticles. (b) The infrared spectrum of CMNC. (c) The infrared spectrum of functionalized CMNC. 
The surface morphology and the diameter of prepared $\mathrm{Fe}_{3} \mathrm{O}_{4}$ magnetic nanoparticles were studied using Atomic Force Microscope (AFM), both two and threedimensional images of magnetite nanoparticles $\mathrm{Fe}_{3} \mathrm{O}_{4}$ were obtained as shown in Fig. 3. The properties of magnetite nanoparticles by AFM have revealed that particle sizes are evenly distributed and particle size was found to be around $(65-90 \mathrm{~nm})$ and the average diameter of $(77.13 \mathrm{~nm})$.The three dimensional surface image shown in Fig. 3 confirms that $\mathrm{Fe}_{3} \mathrm{O}_{4}$ magnetic nanoparticles are spherical in shape and agglomerated in form. Table 1 and Fig. 4 show the particle size distribution of $\mathrm{Fe}_{3} \mathrm{O}_{4}$ magnetic nanoparticles. The results obtained confirm that the most volume percentage 25.23 $\%$ of particle size distribution was at $70 \mathrm{~nm}$ and the lowest volume percentage $0.46 \%$ was at $120 \mathrm{~nm}$.
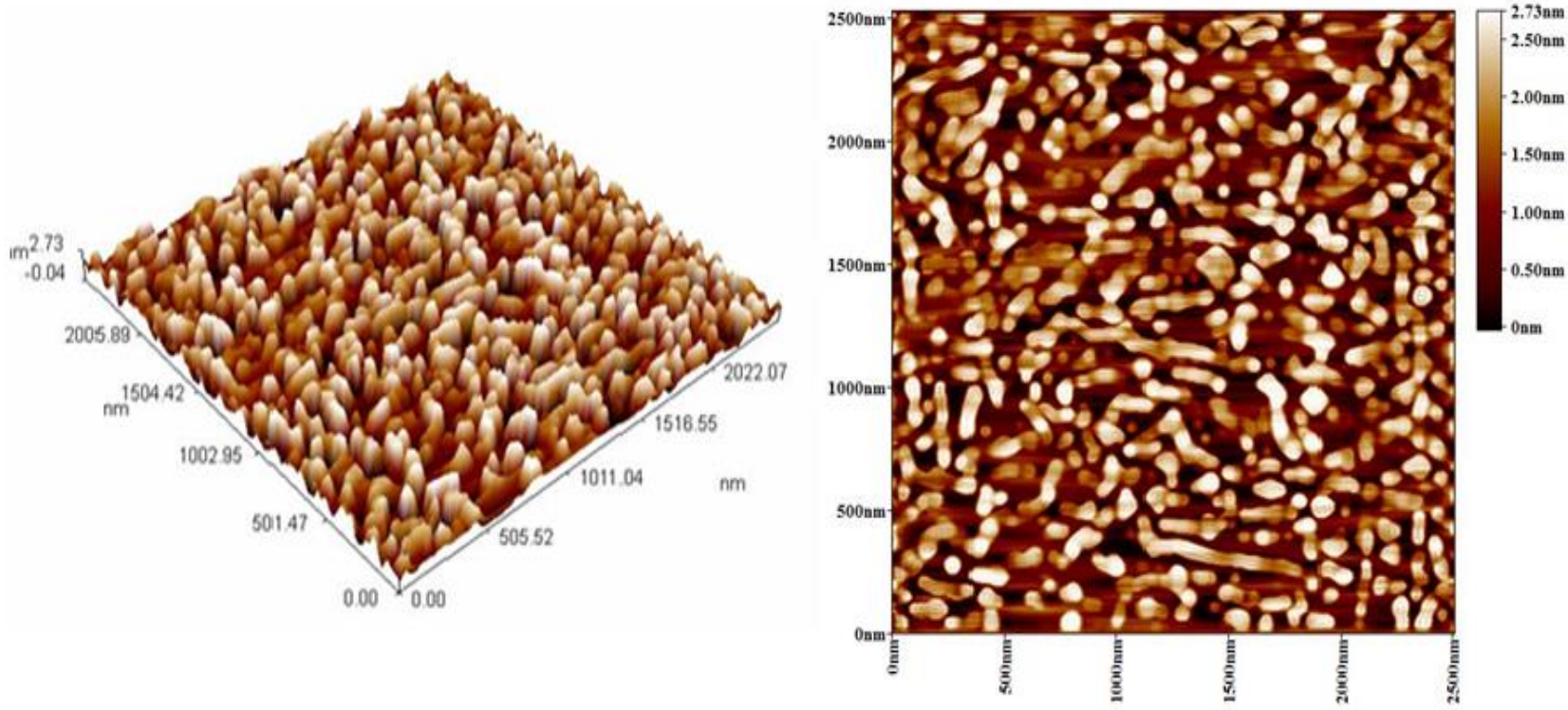

Fig. 3 AFM Three-dimensional surface profile for $\mathrm{Fe}_{3} \mathrm{O}_{4}$ magnetic nanoparticles.

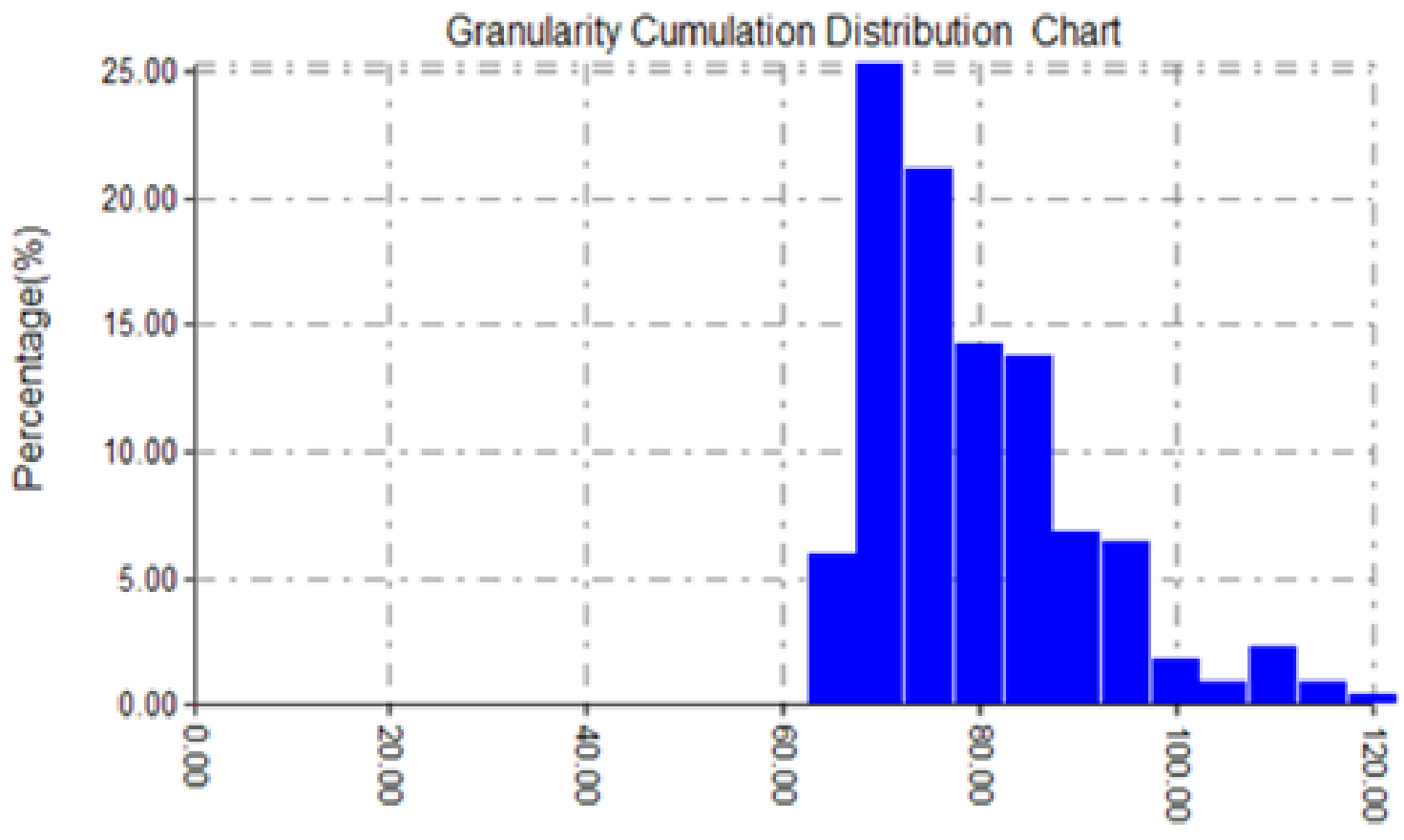

Diameter(nm)

Fig. 4 Bar chart of particle size distribution of $\mathrm{Fe}_{3} \mathrm{O}_{4}$ magnetic nanoparticles. 
Table 1. Particle size distribution of $\mathrm{Fe}_{3} \mathrm{O}_{4}$ magnetic nanoparticles with average diameter of $77.13 \mathrm{~nm}$

\begin{tabular}{|l|l|l|l|l|l|l|l|l|}
\hline $\begin{array}{l}\text { Diameter( } \\
\mathbf{n m})<\end{array}$ & $\begin{array}{l}\text { Volume } \\
(\%)\end{array}$ & $\begin{array}{l}\text { Cumulation( } \\
\%)\end{array}$ & $\begin{array}{l}\text { Diameter } \\
\mathbf{n m})<\end{array}$ & $\begin{array}{l}\text { Volume } \\
(\%)\end{array}$ & $\begin{array}{l}\text { Cumulation } \\
(\%)\end{array}$ & $\begin{array}{l}\text { Diameter } \\
(\mathbf{n m})<\end{array}$ & $\begin{array}{l}\text { Volume( } \\
\%)\end{array}$ & $\begin{array}{l}\text { Cumulation } \\
(\%)\end{array}$ \\
\hline $\mathbf{6 5 . 0 0}$ & $\mathbf{5 . 9 6}$ & $\mathbf{5 . 9 6}$ & $\mathbf{8 5 . 0 0}$ & $\mathbf{1 3 . 7 6}$ & $\mathbf{8 0 . 2 8}$ & $\mathbf{1 0 5 . 0 0}$ & $\mathbf{0 . 9 2}$ & 96.33 \\
$\mathbf{7 0 . 0 0}$ & $\mathbf{2 5 . 2 3}$ & 31.19 & $\mathbf{9 0 . 0 0}$ & $\mathbf{6 . 8 8}$ & $\mathbf{8 7 . 1 6}$ & $\mathbf{1 1 0 . 0 0}$ & $\mathbf{2 . 2 9}$ & $\mathbf{9 8 . 6 2}$ \\
$\mathbf{7 5 . 0 0}$ & $\mathbf{2 1 . 1 0}$ & $\mathbf{5 2 . 2 9}$ & $\mathbf{9 5 . 0 0}$ & $\mathbf{6 . 4 2}$ & $\mathbf{9 3 . 5 8}$ & $\mathbf{1 1 5 . 0 0}$ & $\mathbf{0 . 9 2}$ & 99.54 \\
$\mathbf{8 0 . 0 0}$ & $\mathbf{1 4 . 2 2}$ & $\mathbf{6 6 . 5 1}$ & $\mathbf{1 0 0 . 0 0}$ & $\mathbf{1 . 8 3}$ & $\mathbf{9 5 . 4 1}$ & $\mathbf{1 2 0 . 0 0}$ & $\mathbf{0 . 4 6}$ & $\mathbf{1 0 0 . 0 0}$ \\
\hline
\end{tabular}

Surface morphological images obtained by SEM and the energy dispersive $\mathrm{X}$-ray (EDX) for the $\mathrm{Fe}_{3} \mathrm{O}_{4}$ magnetic nanoparticles as described in Fig. 5. It can be observed that the particles between $60-100 \mathrm{~nm}$ are almost in spherical shape. The collected particles appear, this probably as a result of $\mathrm{Fe}_{3} \mathrm{O}_{4}$ magnetic nanoparticles being a hydrophobic surface, and due to hydrophobic interaction between the particles, which causes the particle to agglomerate and form large clusters. The $\mathrm{Fe}_{3} \mathrm{O}_{4}$ magnetic nanoparticles EDX spectrum confirms the composition of iron (69.8\%) and oxygen (30.2\%). Also, the result is in consistent with those obtained by [Katayoon K. et al., 2014].

A typical SEM and EDX images for the functionalized CMNC shown in Fig. 6. The SEM image explained that the $\mathrm{Fe}_{3} \mathrm{O}_{4}$ nanoparticles are dispersed in the functionalized CMNC. The number and energy of the $\mathrm{X}$ rays emitted from a specimen can be measured by an energy-dispersive spectrometer. The EDX analysis of these particles indicates the existence of iron and oxygen and carbon composition in the functionalized $\mathrm{CMNC}$. The component composition of oxygen, carbon and iron is $38.4,31.1$ and $30.5 \%$, respectively. The nitrogen element is not detected because it is available at a lower rate than the rest of the elements and the nature of the device is not sensitive to nitrogen if it is not in large proportions, these results are in agreement with previously reported by [Vaishnavi S. et al., 2015].
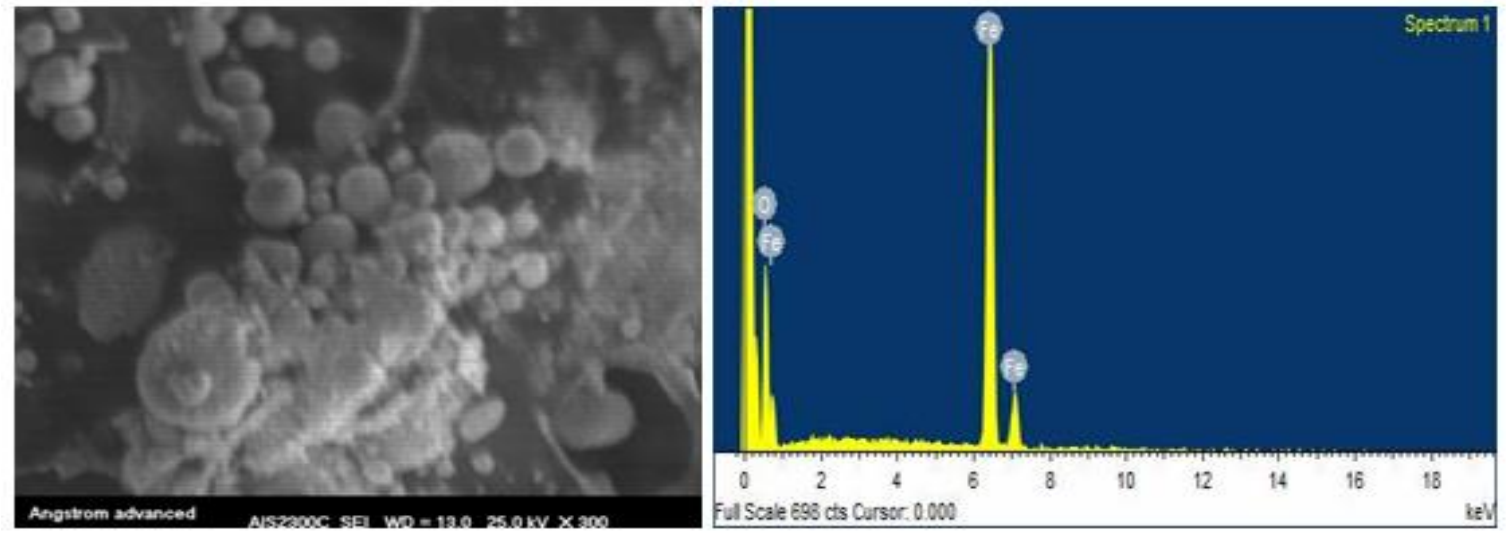

Fig. 5 SEM-EDX images for $\mathrm{Fe}_{3} \mathrm{O}_{4}$ nanoparticles.
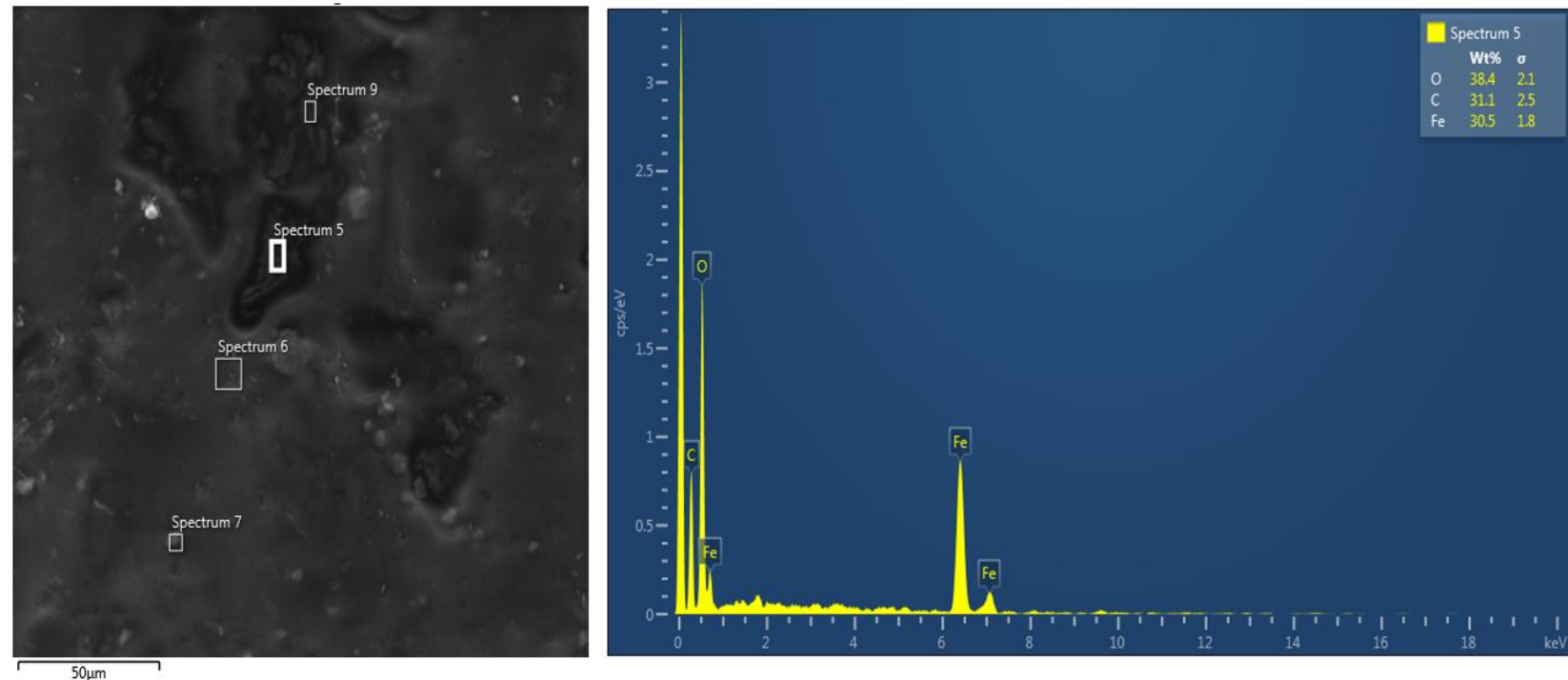

Fig. 6 SEM-EDX images for functionalized CMNC. 
Thermo gravimetric analysis (TGA) curves for the functionalized CMNC is presented in Fig. 7. The curve in the blue line depicts the change in the weight of the sample in percentage with temperature. Three steps weight loss was observed. The first step from $50{ }^{\circ} \mathrm{C}$ to $131.8^{\circ} \mathrm{C} \quad(1 \mathrm{wt} \%)$ can be attributed to the loss of moisture from the sample structure. The second weight loss observed at $131.8{ }^{\circ} \mathrm{C}$ to $301.2^{\circ} \mathrm{C}(44$ wt $\%$ ) is due to the degradation of functionalized $\mathrm{CMNC}$, while the third weight loss between $301.2{ }^{\circ} \mathrm{C}$ to $569.3^{\circ} \mathrm{C}$ (76 wt \%) can be attributed to the decomposition of the functionalized CMNC main chain. The total weight loss is $77.91 \%$ at $585.48{ }^{\circ} \mathrm{C}$. These results are in agreement with previously reported by [Jucély d. et al., 2015].

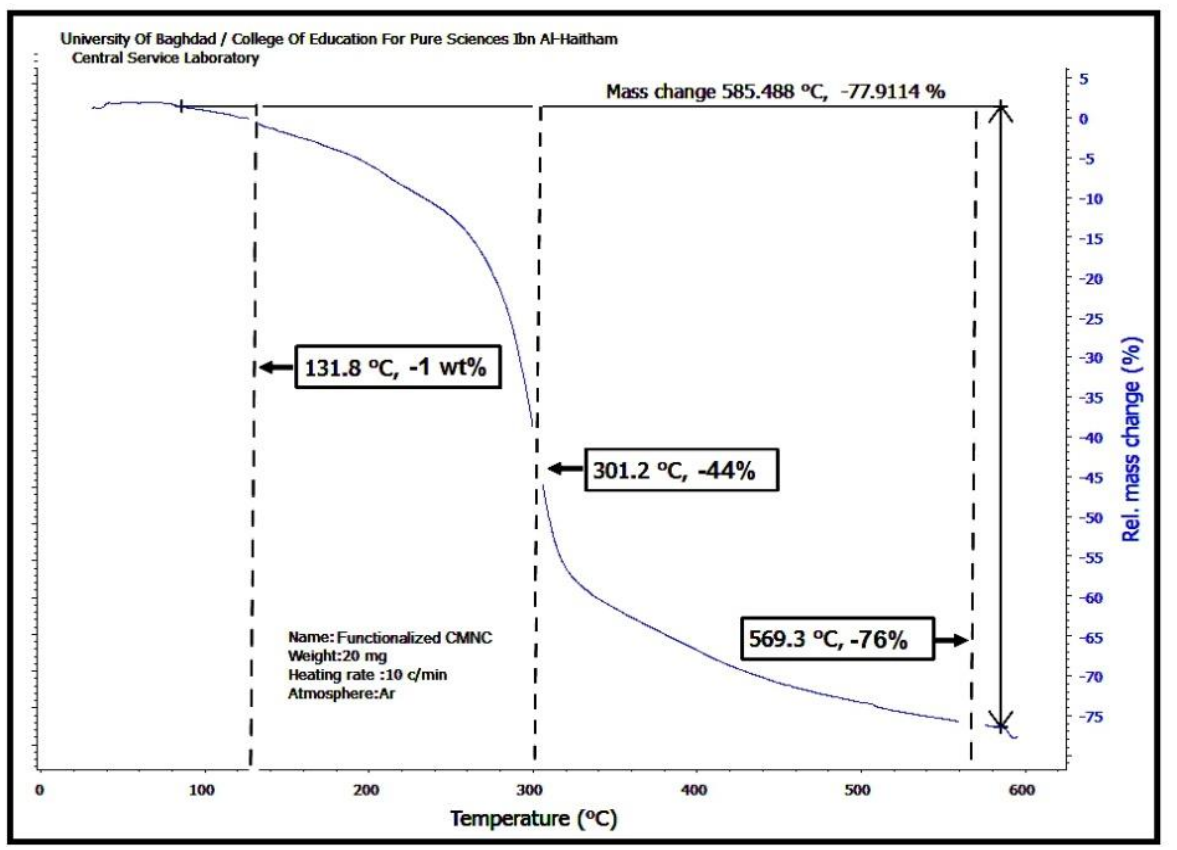

Fig. 7 Thermo-gravimetric analysis of functionalized CMNC.

\section{Batch sorption}

\section{Comparison of the three adsorbents}

A comparative study was carried out between the three tested adsorbents in order to investigate the effectiveness of functional group of chitosan (CS), chitosan magnetic nanocomposite (CMNC) and functionalized CMNC on the sorption of chromium from its aqueous solutions. Fig. 8 showed the chromium sorption for Chitosan (CS), Chitosan magnetic nanocomposite (CMNC) and Functionalized $\mathrm{CMNC}$ at various $\mathrm{pH}$ values.

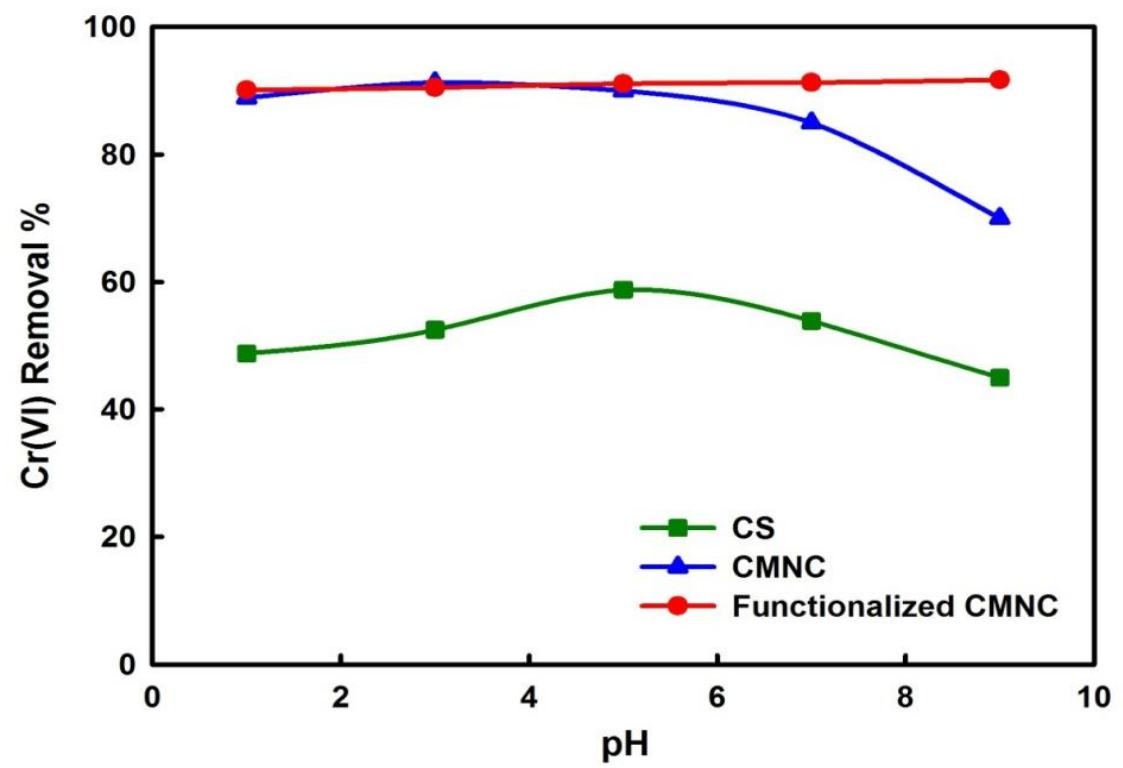

Fig. 8 The effect of pH value on \% $\mathrm{Cr}(\mathrm{VI})$ removal using Chitosan (CS), Chitosan magnetic 
nanocomposite (CMNC) and Functionalized CMNC adsorbents at initial concentration $=30 \mathrm{mg} / \mathrm{l}$, adsorbent dose $=0.1 \mathrm{gm}$, contact time $=200 \mathrm{~min}$.

From this Figure, it is clearly that the highest percentage sorption of Chromium by chitosan was observed at $\mathrm{pH}=$ 5 with increase in $\mathrm{pH}$ from 1 to 9 the percentage sorption of chromium decreased from $58.8 \%$ to $48.8 \%$, there are still some limitations in the application of the chitosan based materials because chitosan can be applied only in the acidic solution where $-\mathrm{NH}_{2}$ groups of chitosan are protonated. As $\mathrm{pH}$ increased, amine groups become less active towards $\mathrm{Cr}(\mathrm{VI})$. While the $\mathrm{Fe}_{3} \mathrm{O}_{4}$ is coated with chitosan (CMNC), the percentage removal increases to $94.5 \%$ in the acidic medium. However, in case of addition of hexamine and at the basic medium, the percentage sorption of Chromium reached $91.7 \%$ at $\mathrm{pH}=$ 9.

\subsubsection{Effect of Sorbent Dose}

Experiments were done to establish an appropriate sorbent Chitosan (CS) and Functionalized CMNC) dose for Chromium removal with the results shown in Fig. 9. From the figure it seem that by increasing the dosage of sorbent the removal ratio increases as a result of increasing surface area of adsorption. The percentage of chromium removed increased from 16 to $58.8 \%$ with increasing the dosage from 0.02 to $0.1 \mathrm{~g}$ of chitosan, While increasing in the dosage from 0.02 to $0.1 \mathrm{~g}$ of functionalized $\mathrm{CMNC}$, the percentage of chromium removed increased from 51.6 to $91.7 \%$. This dosage agreement with [Auta M. and Hameed B., 2014; Dong W. et al., 2012].

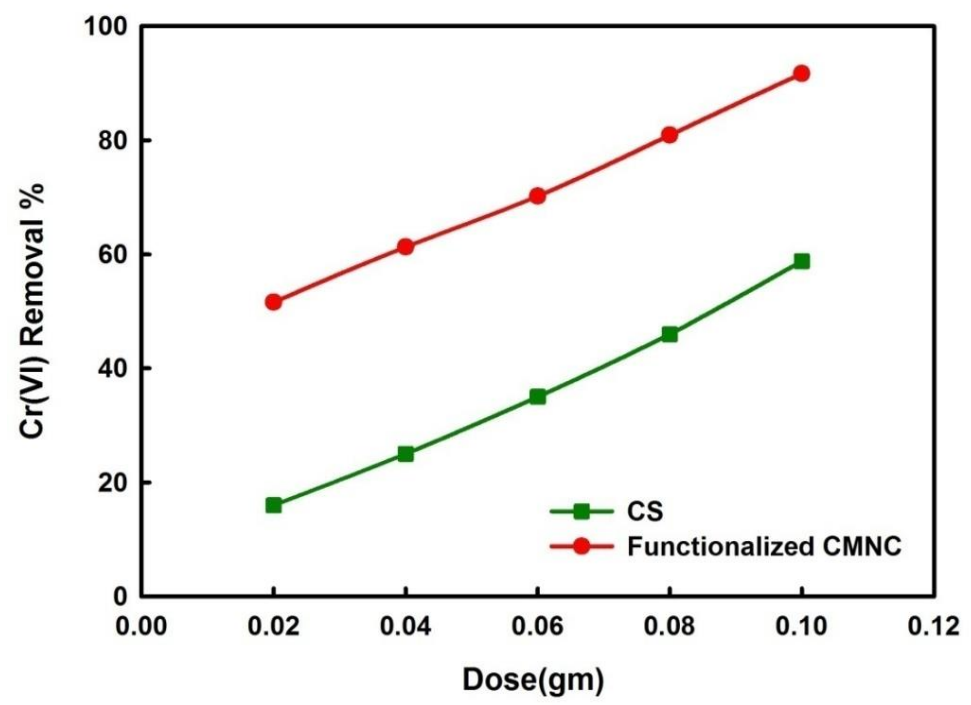

Fig. 9 Effect of Chitosan (CS) and Functionalized CMNC Dose using $(\mathrm{Co}=30 \mathrm{mg} / \mathrm{l}, 298 \mathrm{~K}$, contact time $=200 \mathrm{~min}$ and r.p.m=200).

\section{Effect of Contact Time}

The effect of contact time for removal of Chromium by the chitosan (CS) and Functionalized CMNC as is shown in Fig. 10. From figure we note that, the rate of the chromium is rapid adsorption in the first $50 \mathrm{~min}$ and, thereafter, the adsorption rate increased gradually and the adsorption reached equilibrium at $200 \mathrm{~min}$ for $\mathrm{CS}$ and $150 \mathrm{~min}$ for Functionalized CMNC. Increasing the contact time up to $200 \mathrm{~min}$ showed that the chromium removal increased by $58.8 \%$ over those obtained at 200 min , while in functionalized CMNC adsorption reached equilibrium at $150 \mathrm{~min}$ and this agreement with those of [Hua Y. et al., 2010; George Z. et al., 2013]. 

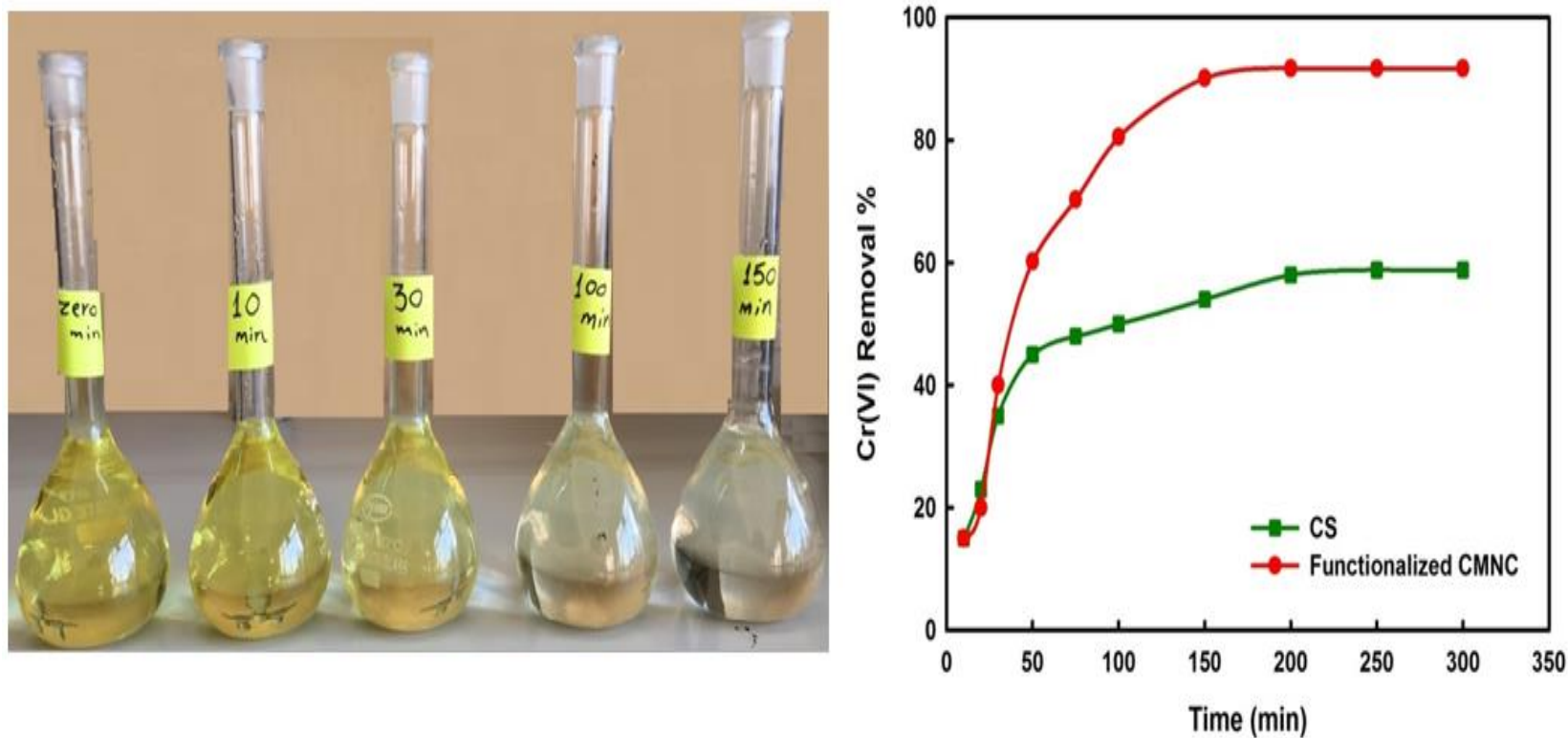

Fig. 10 Effect of contact time on adsorption of $\mathrm{Cr}(\mathrm{VI})$ by the chitosan $(\mathrm{CS})$ and functionalized $\mathrm{CMNC}$ using $\left(\mathrm{C}_{\mathrm{o}}=30\right.$ $\mathrm{mg} / \mathrm{l}$, adsorbent dose=0.1gm, $298 \mathrm{~K}$, and rpm=200).

\section{Effect of Initial Chromium Concentration}

The effect of initial chromium concentration on the removal of chromium by chitosan and functionalize CMNC is shown in Fig. 11. From figure we note that, the amount of sorbed chromium per unit mass of chitosan and functionalized CMNC (qe) increased with increasing the initial concentration of chromium $\mathrm{C}_{\mathrm{o}}$ from $10 \mathrm{mg} / \mathrm{L}$ to 70 $\mathrm{mg} / \mathrm{L}$, although the percentage chromium removal decreased with the increase in the initial concentration of chromium. The initial concentration provides necessary driving force by the concentration gradient $\left(\Delta C=C_{0}-C_{e}\right)$ to overcome the resistance to the mass transfer of chromium between the aqueous and the solid phases. This result was in a good agreement with the finding of [Nguyen $\mathbf{N}$. et al., 2012; Xin j. et al., 2010].

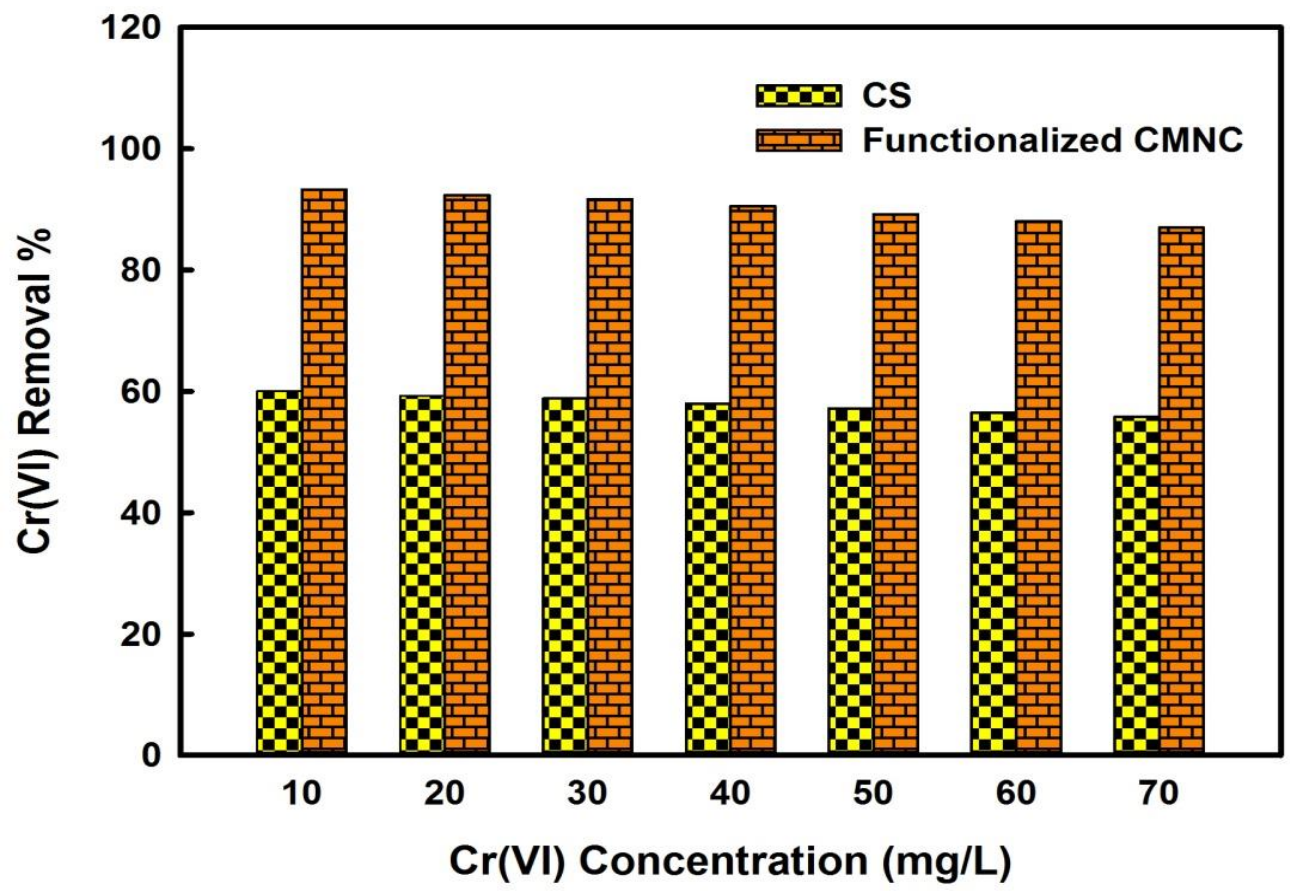

Fig. 11 Effect of initial Chromium concentration on the amount of chromium adsorbed by chitosan(CS) and functionalized CMNC using $\left(C_{0}=30 \mathrm{mg} / \mathrm{l}\right.$, adsorbent dose=0.1gm, $298 \mathrm{~K}$, and r.p.m=200). 


\section{Effect of Temperature}

The effect of temperature on the removal of Chromium by chitosan(CS) and functionalized CMNC at 30, 50, and $70^{\circ} \mathrm{C}$ is shown in Fig. 12. There is no change in removal rate was noted $(58.8,62.4$, and $66.23 \%$, respectively) for chitosan and $(94.5,95.6$ and $96.7 \%$, respectively) for functionalized $\mathrm{CMNC}$, materials can be utilized in ambient temperature, thus reducing the energy costs of processes used to remove environmental contaminants. This outcome is in a good agreement with the results noted by [Peng w. et al., 2013].

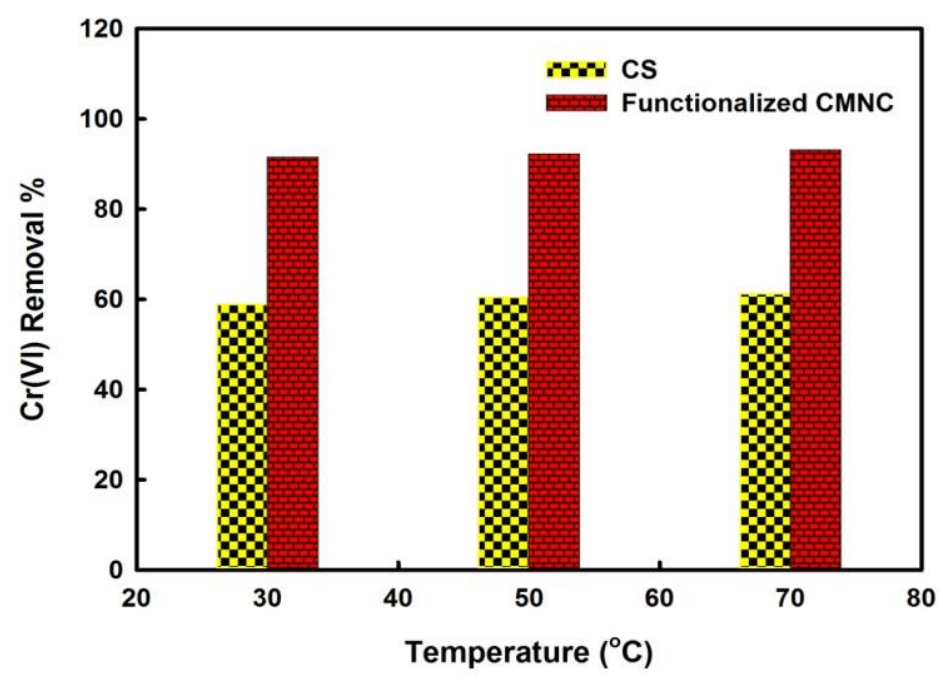

Fig. 12 Effect of temperature on adsorption of Chromium by $0.1 \mathrm{~g}$ chitosan(CS) and functionalized CMNC using $\left(\mathrm{C}_{\mathrm{o}}=30\right.$, adsorbent dose $=0.1 \mathrm{gm}$, time $=200 \mathrm{~min}$, r.p.m=200).

\section{Equilibrium adsorption isotherm studies}

In order to indicate the behavior of sorption capacity of functionalized CMNC, sorption isotherms have been studied by three linearized isotherm models, Langmuir [Langmuir, 1916], Freundlich [Freundlich, 1906] and Temkin [Temkin and Pyzhev, 1940]. The isotherm models fitting to the experimental data were carried out using their non-linear equations expressed as:

$$
\begin{array}{ll}
\mathrm{q}_{\mathrm{e}}=\frac{\mathrm{q}_{\max } \mathrm{bC}_{\mathrm{e}}}{1+\mathrm{bC}_{\mathrm{e}}} & \text { Langmuir model } \\
\mathrm{q}_{\mathrm{e}}=\mathrm{K}_{\mathrm{f}} \mathrm{C}_{\mathrm{e}}^{1 / \mathrm{n}} & \text { Freundlich model } \\
\mathrm{q}_{\mathrm{e}}=\frac{\mathrm{RT}}{\mathrm{b}_{\mathrm{T}}} \operatorname{lnK}_{\mathrm{T}} \mathrm{C}_{\mathrm{e}} & \text { Temkin model }
\end{array}
$$

Where $C_{e}(\mathrm{mg} / \mathrm{L})$ and $\mathrm{q}_{\mathrm{e}}(\mathrm{mg} / \mathrm{g})$ are the equilibrium concentration and the amount of $\mathrm{Cr}(\mathrm{IV})$ adsorbed, respectively; $\mathrm{q}_{\max }(\mathrm{mg} / \mathrm{g})$ and $\mathrm{b}(\mathrm{L} / \mathrm{g})$ are the monolayer adsorption capacity and affinity of functionalized CMNC towards chromium, respectively. The $\mathrm{K}_{\mathrm{f}}((\mathrm{mg} / \mathrm{g})$ $(\mathrm{L} / \mathrm{mg}) 1 / \mathrm{n}$ ) and $\mathrm{n}$ (dimensionless) are the Freundlich constants relaying information on the adsorption extent and degree of nonlinearity between the adsorption and the solution concentration, respectively. $K_{T}$ the Temkin equilibrium binding constant $(\mathrm{L} / \mathrm{g})$ corresponding to the maximum binding energy, $\mathbf{b}_{\mathbf{T}}$ is Temkin isotherm constant and is related to heat of sorption $(\mathrm{KJ} / \mathrm{mol}), \mathbf{R}$ is the universal gas constant $(8.314 \mathrm{~J} / \mathrm{mol} \mathrm{K})$, and $\mathbf{T}$ is absolute temperature $(\mathrm{K})$, sorption isotherms have been studied for three linearized isotherm models (Langmuir, Freundlich and Temkin) at $298 \mathrm{~K}$. Plots are given in Fig. 13 


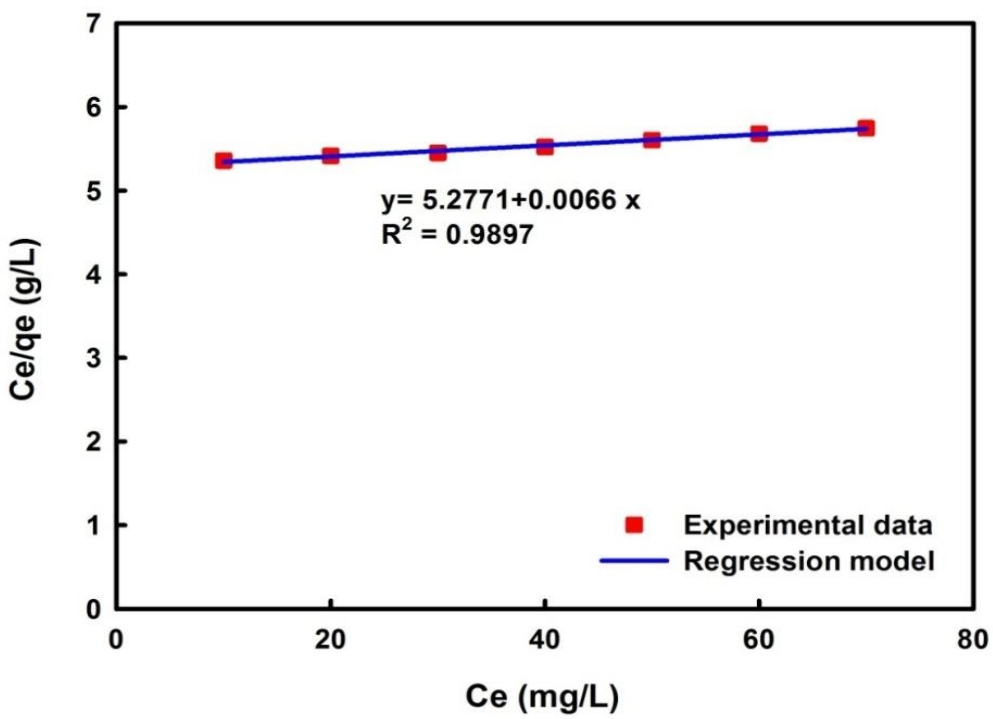

(a)

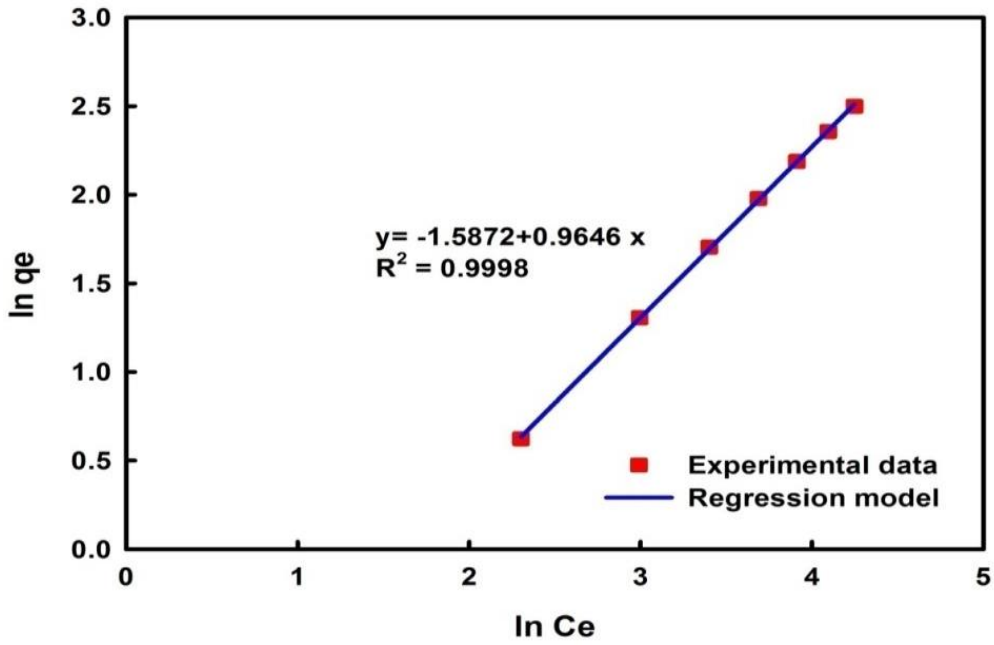

(b)

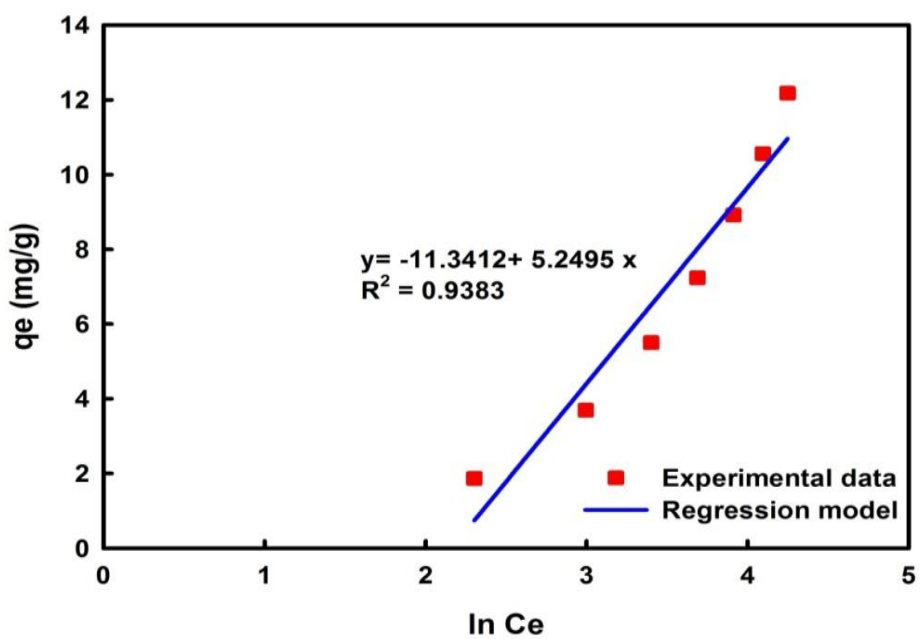

(c)

Fig. 13 (a) Langmuir Isotherm model for functionalize CMNC

(b) Freundlich Isotherm model for functionalize CMNC.

(c)Temkin Isotherm model for functionalize CMNC. 
The models parameters and the correlation coefficient $\left(\mathrm{R}^{2}\right)$ for each model obtained are summarized in Table 2. It can be seen from this Table that the coefficient of determination values for Langmuir model, $\mathrm{R}^{2}=0.9897$, was obtained and that's acceptable results. Freundlich
Isotherm model, $\mathrm{R}^{2}=0.9998$ were obtained and that's a good agreement.

The Temkin Isotherm model, $\mathrm{R}^{2}=0.9383$ were obtained and that's agreement. The high $\mathrm{R}^{2}$ values (0.999) of Freundlich isotherm indicates that the adsorption follow Freundlich model more than the other two models used.

Table 2: Model parameters for the sorption of Chromium.

\begin{tabular}{|c|c|c|c|c|c|c|c|c|c|c|c|}
\hline \multirow{2}{*}{ Adsorbent } & \multicolumn{5}{|c|}{ Langmuir } & \multicolumn{3}{|c|}{ Freundlich } & \multicolumn{3}{|c|}{ Temkin } \\
\hline & $\mathrm{T}(\mathrm{K})$ & $\begin{array}{l}\mathrm{q}_{\max } \\
(\mathrm{mg} / \mathrm{g})\end{array}$ & $\mathrm{b}(\mathrm{l} / \mathrm{mg})$ & $\mathrm{R}^{2}$ & $\mathrm{R}_{\mathrm{L}}$ & $\mathrm{K}_{\mathrm{f}}(\mathrm{mg} / \mathrm{g})$ & $\mathrm{n}$ & $\mathrm{R}^{2}$ & $\mathrm{~K}_{\mathrm{T}}(1 / \mathrm{g})$ & $\mathrm{b}_{\mathrm{T}}(\mathrm{KJ} / \mathrm{mol})$ & $\mathrm{R}^{2}$ \\
\hline $\begin{array}{l}\text { functionalize } \\
\text { CMNC }\end{array}$ & 298 & 151.51 & 0.00125 & 0.989 & 0.963 & 0.20 & 1.03 & 0.999 & 0.11 & 5.24 & 0.938 \\
\hline
\end{tabular}

\section{Kinetic of sorption}

The kinetic experiment data were modeled by pseudofirst-order and pseudo-second-order kinetic equations. The nonlinear expressions of the models are expressed as:

$$
\begin{aligned}
& \mathrm{q}_{\mathrm{t}}=\mathrm{q}_{\mathrm{e}}\left(1-\mathrm{e}^{-\mathrm{k}_{1} \mathrm{t}}\right) \quad \text { for pseudo 1order } \\
& \mathrm{q}_{\mathrm{t}}=\frac{\mathrm{k}_{2} \mathrm{q}_{\mathrm{e}}^{2} \mathrm{t}}{\left(1+\mathrm{k}_{2} \mathrm{q}_{\mathrm{e}} \mathrm{t}\right)} \quad \text { for pseudo 2order }
\end{aligned}
$$

Where $\mathrm{q}_{\mathrm{e}}$ and $\mathrm{q}_{\mathrm{t}}(\mathrm{mg} / \mathrm{g})$, are the amount of chromium adsorbed at equilibrium and at any time $\mathrm{t}(\mathrm{min})$, respectively; $\mathrm{k}_{1}\left(\mathrm{~h}^{-1}\right)$ and $\mathrm{k}_{2}(\mathrm{~g} / \mathrm{mg} \mathrm{h})$ are the pseudo-firstorder and pseudo-second-order rate constants, respectively.

The kinetics of the chromium sorption on functionalized CMNC was screening by using pseudofirst and second order kinetics models as shown in Fig. 14

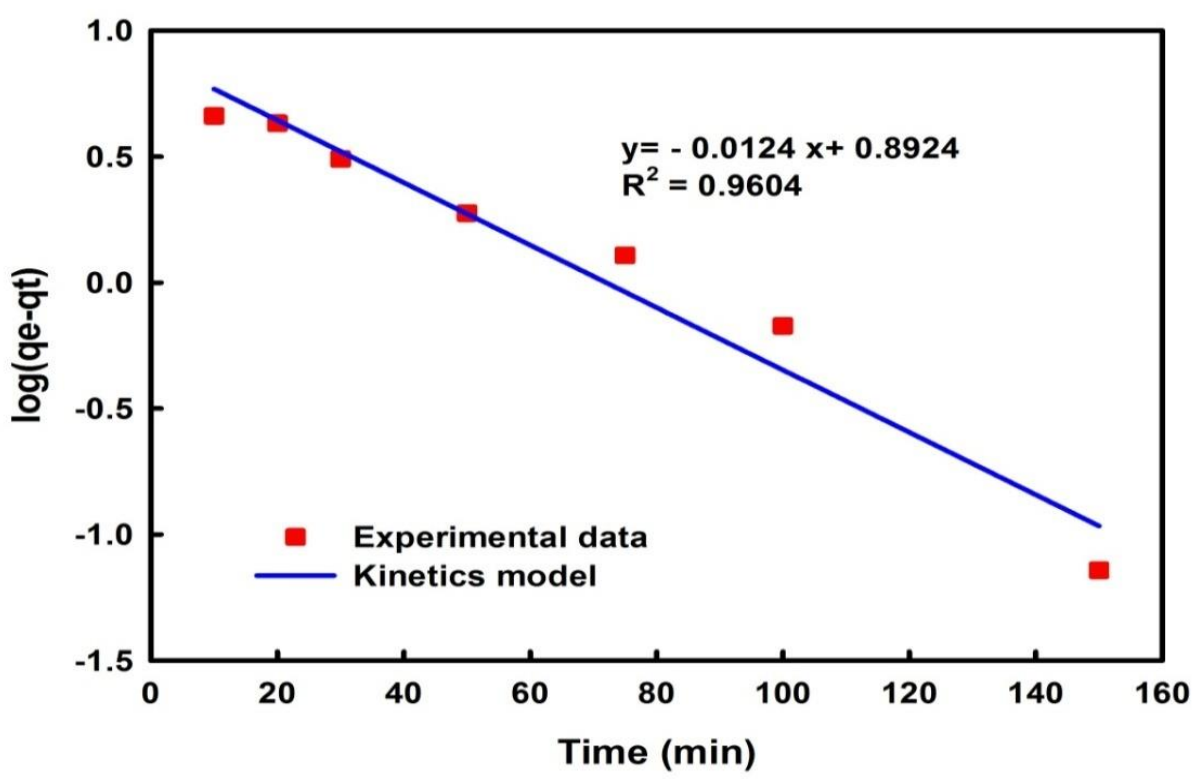

(a) 


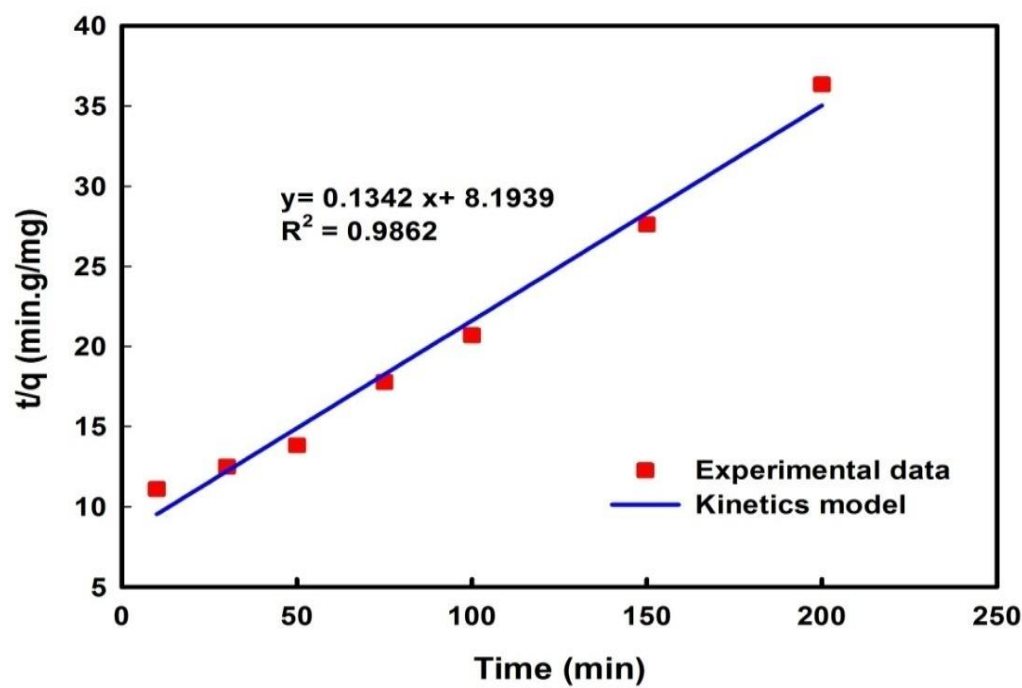

(b)

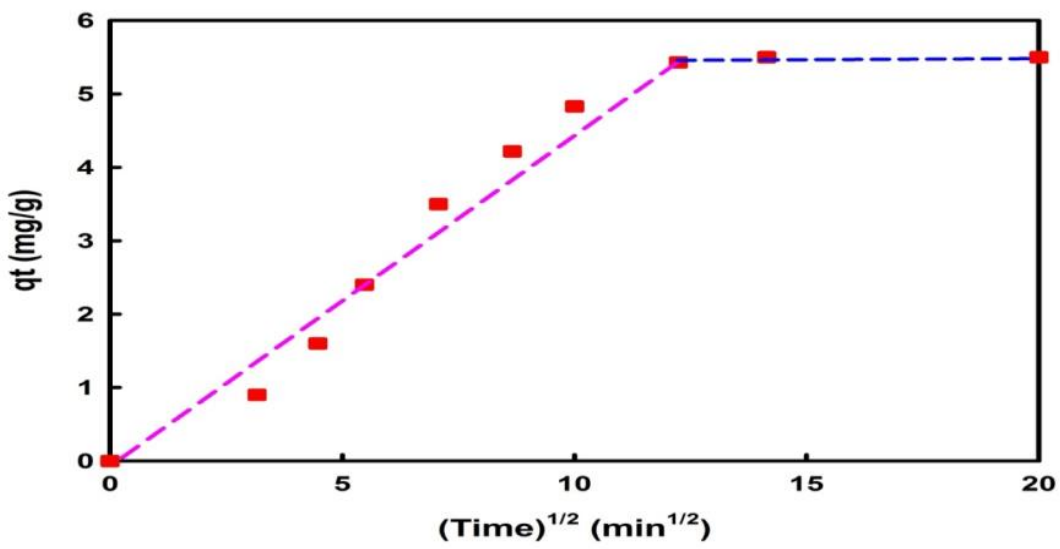

(c)

Fig. 14 (a)Pseudo-first order kinetics model for functionalize CMNC. (b) Pseudo- second order kinetics model for functionalize CMNC. (c)Intraparticle Diffusion model for functionalized CMNC.

The plot of values of qt vs. $t$ was used to determine the $\mathrm{q}_{\mathrm{e}}$ and $\mathrm{k}_{1}$ parameters which shown in Table 3 . The results showed that the second-order model has the best fit for experimental data. This was observed by a high correlation coefficient (R2) of 0.9862 .

Table (3): Pseudo-first order and pseudo-second order kinetic models for the sorption of chromium on the functionalized

CMNC.

\begin{tabular}{|c|c|c|c|c|c|c|c|c|}
\hline \multirow{2}{*}{ Adsorbent } & \multicolumn{5}{|c|}{ Pseudo- first order } & \multicolumn{3}{|c|}{ Pseudo- second order } \\
\hline & $\begin{array}{l}\mathbf{T}( \\
\mathbf{K}) \\
\end{array}$ & $q_{\exp }(\mathrm{mg} / \mathrm{g})$ & $\mathbf{q}_{\text {calc}}(\mathrm{mg} / \mathrm{g})$ & $\mathrm{K} 1\left(\min ^{-1}\right)$ & $\mathbf{R}^{2}$ & qcalc $(\mathbf{m g} / \mathrm{g})$ & $K_{2}$ (g/mg.min) & $\mathbf{R}^{2}$ \\
\hline $\begin{array}{c}\text { functionalize } \\
\text { CMNC }\end{array}$ & 298 & 5.502 & 7.805 & 0.0285 & $\begin{array}{c}0.96 \\
04\end{array}$ & 7.451 & 0.00219 & $\begin{array}{c}0.9 \\
86 \\
2\end{array}$ \\
\hline
\end{tabular}

\section{Sorption Thermodynamics}

The adsorption process of functionalized CMNC and $\mathrm{Cr}(\mathrm{VI})$ equilibrium surface interaction was studied by adopting Gibb's expression over temperature range of 30 $-50{ }^{\circ} \mathrm{C}$. The Gibb's free energy $(\Delta \mathrm{G})$ of the process was determined using the following equation:

$$
\Delta \mathrm{G}=-\mathrm{RT} \ln \mathrm{K}_{\mathrm{c}}
$$

And the enthalpy $(\Delta \mathrm{H})$ and entropy $(\Delta \mathrm{S})$ of activation the $\mathrm{Cr}(\mathrm{VI})$ adsorption were determind from free energy aquation :

$$
\ln \mathrm{K}_{\mathrm{c}}=\frac{\Delta \mathrm{G}}{\mathrm{RT}}=\frac{\Delta \mathrm{S}}{\mathrm{R}}-\frac{\Delta \mathrm{H}}{\mathrm{RT}}
$$

Where $\mathrm{R}$ is the universal gas constant (8.314 $\mathrm{J} / \mathrm{Kmol}) ; \mathrm{T}$, absolute temperature $(\mathrm{K}) ; \mathrm{Kc}$ distribution coefficient expressed as $\mathrm{Kc}=\mathrm{qe}$ (adsorbent)/Ce (solution), and from the plot of $\operatorname{lnKc}$ against $1 / \mathrm{T}$, the intercept and 
slope were used to determine values of $\Delta \mathrm{H}$ and $\Delta \mathrm{S}$, respectively, intraparticle diffusion model was applied to the experimental data as shown in Fig. 15 and the

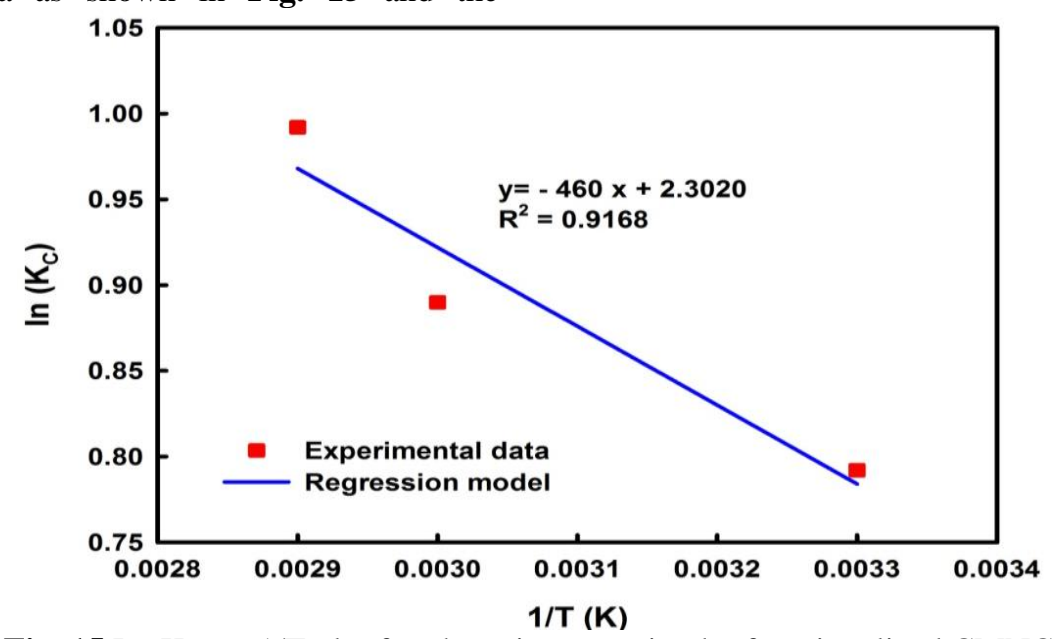

Fig. 15 Ln Kc vs. 1/T plot for chromium sorption by functionalized CMNC.

It is noted from the figure that the positive values of $\Delta \mathrm{G}$ were positive indicating that the total $\mathrm{Cr}$ biosorption process not spontaneous and therefore requires some energy from an external source in order to occur.[Dogan M.et

al.,2009], while the positive value of enthalpy $\Delta \mathrm{H}$ indicates that the sorption is endothermic. $\Delta \mathrm{S}$ were positive indicating that the increased randomness at the solid solution interface during the fixation of adsorbents on the active sites of the adsorbent.

\subsubsection{Regeneration of Functionalized CMNC}

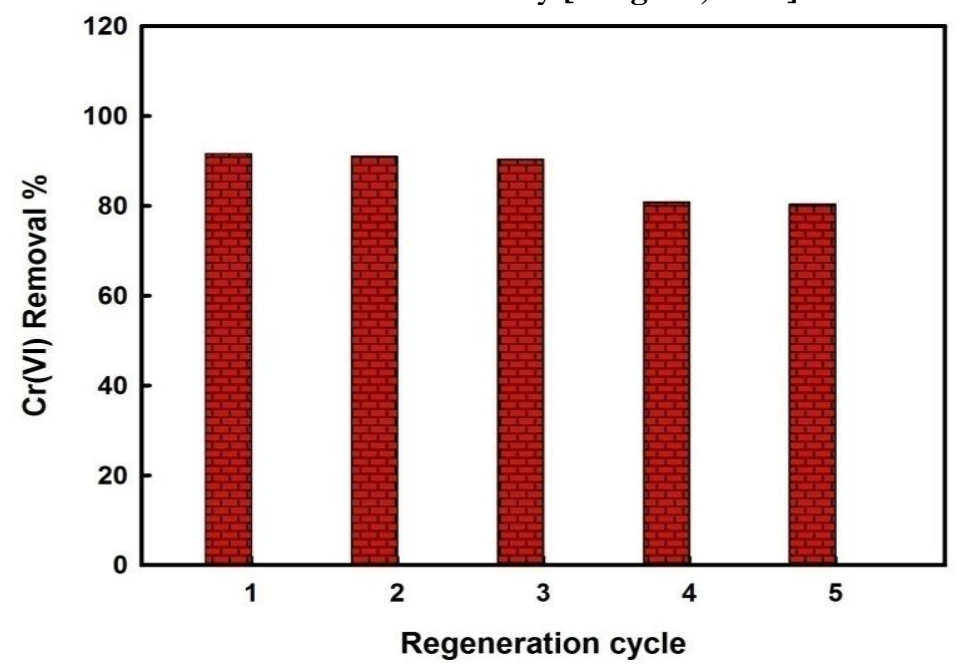

Fig. 16 Regeneration of functionalized of CMNC.
Note that absorption capacity decreased slightly with increased cycles. In the first five cycles, adsorption efficiency of functionalized CMNC remained almost constant : having been refurbished three times, the $\mathrm{Cr}$ removal rate was still more than $80 \%$. This fact suggests that functionalized CMNC can be used as a reusable to absorb the $\mathrm{Cr}$ adsorption from aqueous.
The reuse of an adsorbent is important property for practical applications. In this study, a mixture of the solution of $0.1 \mathrm{~mol} / \mathrm{L} \mathrm{NaCl}$ was use as regeneration desorption agent. Fig. 16 show the five reusability cycles of functionalized of CMNC. It can be seen that a slightly decreased in adsorption efficiency with cycle increased and remained almost constant for the first three cycles. These results show that the functionalized CMNC can be used as a reusable for $\mathrm{Cr}$ adsorption from aqueous; this result was in a good agreement with the finding reported by [Peng W., 2013]

\section{Conclusions}

The $\mathrm{Fe}_{3} \mathrm{O}_{4}$ magnetic nanoparticles and chitosan magnetic nanocomposite were successfully prepared by chemical co-precipitation technique and Ex situ process respectively. Amination of CMNC with hexamine to get functionalized $\mathrm{CMNC}$ revealed a significant effects for $\mathrm{Cr}(\mathrm{VI})$ removal in wider range of $\mathrm{pH}$. The characterization results of the prepared $\mathrm{Fe}_{3} \mathrm{O}_{4}$ magnetic nanoparticles, $\mathrm{CMNC}$ and functionalized $\mathrm{CMNC}$ was confirmed the composition, structure and the thermal 
stability of each prepared samples. The adsorption results show that the functionalized CMNC possessed high activity for $\mathrm{Cr}(\mathrm{VI})$ removal in any condition of acidic, neutral and basic solutions with the percentage sorption of chromium reached to $91.7 \%$. The sorption isotherms fitted with the Langmuir, Freundlich and Temkin models show that the Freundlich isotherm model had the best fit with $\mathrm{R}^{2}=0.9974$ with functionalized CMNC. The kinetic data for $\mathrm{Cr}(\mathrm{VI})$ sorption with functionalized CMNC was found that fitted well with the pseudo-second order kinetic model. The functionalized CMNC reuse indicates that the adsorbents have an absorption capacity higher than $80 \%$ after five regeneration cycles.

\section{References}

[1]. Auta M. and Hameed B.H, (2014), "Chitosan Clay Composite As Highly Effective and Low Cost Adsorbent For Batch and Fixed Bed Adsorption of Methylene Blue".

[2]. Dogan M., Abak H. and Alkan M., (2009), "Adsorption of Methylene Blue On To Hazenut Shell".

[3]. Dong C., W. Chen and C. Liu, (2014), “ Preparation of Novel Magnetic Chitosan Nanoparticle and Its Application For Removal of Humic Acid From Aqueous Solution", 1067-1076.

[4]. Dong Wan Cho, Byong-Hun Jeon, Chul-Min Chon, Yongje Kim, Franklin W. Schwartz, Eung-Seok Lee and Hocheol Song, (2012), "A Novel Chitosan/Clay/Magnetite Composite For Adsorption of $\mathrm{Cu}(\mathrm{II})$ and $\mathrm{As}(\mathrm{V})$ ".Environ. Manage. 91 , 798-806.

[5]. Freundlich H.M.F. , (1906), "Over The Adsorption In Solution",J. Phys. Chem., Pp. 385-471.

[6]. George Z. Kyzas and Eleni A. Deliyanni, (2013), "Mercury(II) Removal With Modified Magnetic Chitosan Adsorbents".

[7]. Hong Li, (2016), "Global Trends \& Challenges In Water Science, Research and Management”, Second Edition, 4.

[8]. Hua Yue Zhu, Ru Jiang and Ling Xiao, (2010), "Adsorption of An Anionic Azo Dye By Chitosan/Kaolin/ $\Gamma-\mathrm{Fe} 2 \mathrm{O} 3$ Composites".

[9]. Jucély Dos Santos Menegucci, Mac-Kedson Medeiros Salviano Santos, Diego Juscelino Santos Dias, Juliano Alexandre Chaker and Marcelo Henrique Sousa, (2015), " One-Step Synthesis of Magnetic Chitosan For Controlled Release of 5-hydroxytryptophan".

[10]. Katayoon Kalantari, Mansor B. Ahmad, Kamyar Shameli, Mohd Zobir Bin Hussein, Roshanak Khandanlou, and Hajar Khanehzaei, (2014), "SizeControlled Synthesis of Fe3O4 Magnetic Nanoparticles in the Layers of Montmorillonite".

[11]. Khalid Z. Elwakeel, (2010), " Removal of CR(VI) From Alkaline Aqueous Solution Using Chemically Modified Magnetic Chitosan Resins", New Cairo City, Egypt.

[12]. Kyzas, G.Z., and Lazaridis, (2009), " Reactive and basic dyes removal by sorption onto chitosan derivatives", J. Colloid Interface Sci. 331(1), 32-3.
[13]. Langmuir Irving, (1916), " The Constitution and Fundamental Properties of Solids and Liquids Part I. Solids".

[14]. Nguyen Ngoc Thinh, Pham Thi Bich Hanh, Le Thi Thanh Ha, Le Ngoc Anhc, Tran Vinh Hoang, Vu Dinh Hoang, Le Hai Dang and Nguyen Van Khoi, (2012), "Chitosan-Magnetite Nanoparticles For Removal of Cr(VI) From Aqueous Solution”.

[15]. Peng Wang, Tingguo Yan and Lijuan Wang, (2013a), "A Novel Chitosan/Clay/Magnetitecomposite For Adsorption of $\mathrm{Cu}(\mathrm{II})$ And $\mathrm{As}(\mathrm{V}) "$.

[16]. Peng Wang, Tingguo Yan and Lijuan Wang, (2013b), "Removal of Congo Red From Aqueous Solution Using Magnetic Chitosan Composite Microparticles", 6029

[17]. Pooja Singh and R. Nagendran, (2013), "A Comparative Study of Sorption of Chromium (III) Onto Chitin and Chitosan".

[18]. Shahriar Mahdavi ,Mohsen Jalali and Abbas Afkhami, (2012), "Removal of Heavy Metals From Aqueous Solutions Using Fe3O4, Zno, and Cuo Nanoparticles".

[19]. Temkin, M.J. and Pyzhev V., (1940), "Recent Modifications To Langmuir Isotherms", Acta Physiochim. USSR 12: 217-222.

[20]. Thinh N.N., P.T.B. Hanh, L.T.T. Ha, L.N. Anh, T.V. Hoang and V.D. Hoang, (2013), "Magnetic Chitosan Nanoparticles For Removal of $\mathrm{Cr}(\mathrm{Vi})$ From Aqueous Solution", 1214-8.

[21]. Vaishnavi S., Sureshkumar, C. Kiruba G. Danie, Ruckmani K. and Sivakumar M., (2015), "Fabrication of Chitosan-Magnetite Nanocomposite Strip For Chromium Removal".

[22]. Waldon RD, (2008), "Infrared Spectra of Ferrites", J Phys Rev, 1955(99):1727.

[23]. Xin Jiang Hu, Jing-Song Wang, Yun-Guo Liu, Xin Li, Guang-Ming Zeng, Zheng-Lei Bao, Xiao-Xia Zeng, An-Wei Chen and Fei Long, (2010), "Adsorption of Chromium (VI) By Ethylenediamine-Modified CrossLinked Magnetic Chitosan Resin: Isotherms, Kinetics and Thermodynamics". 